\title{
AUTORIA CONTRA TRADUÇÃO OU TRADUÇÃO COMO AUTORIA: MILAN KUNDERA, JORGE LUIS BORGES E O FIM DO INDIVÍDUO ${ }^{1}$
}

\author{
Pere Comellas \\ Universitat de Barcelona \\ perecomellas@ub.edu
}

\begin{abstract}
Resumo: A tradução tem-se considerado com frequência uma atividade subalterna à criação. No entanto, muitas das obras catalogadas como sendo de autor, e até canônicas e basilares, aproximam-se bastante da tradução. Shakespeare reciclava histórias e Diderot traduzia Sterne do jeito dele. Não se poderia classificar a tradução como mais um gênero literário? Essa é a perspectiva defendida por Borges, e, pelo contrário, contestada por Kundera. Enquanto Borges questiona que a precedência deva implicar preeminência, Kundera sente a crise da autoria como um atentado contra o indivíduo. O fim da submissão da tradução tem de ser necessariamente o fim do reconhecimento da criatividade?
\end{abstract}

Palavras chave: tradução literária, autoria, rescrita, rol do tradutor.

\begin{abstract}
Translation has often been seen as an activity subordinate to creation. However, numerous works considered as by an author, even essential works in the literary canon, are very close to translation. Shakespeare recycled stories and Diderot translated Sterne in his own way. Can translation not be viewed as just another literary genre? This is the perspective defended by Borges, but strongly opposed by Kundera. Whereas Borges questions whether precedence has to mean pre-eminence, Kundera understands the crisis of authorship as an attack on the individual. Does the end of the submission of the translation necessarily have to be the end of the recognition of creativity?
\end{abstract}

Keywords: literary translation, authorship, rewriting, role of translator. 


\section{Você não está na sua casa}

No livro Os Testamentos Traídos, Milan Kundera conta que, no ano 1937, Stravinski e Ansermet brigam por causa de um desacordo artístico. Ansermet vem de dirigir uma obra de Stravinski em cuja execução introduziu alguns cortes. O compositor, molesto, escreve a Ansermet, dizendo que, antes de recortar sua obra, prefere que não a interprete. Ansermet pede que lhe permita pelo menos suprimir certo fragmento. Evidentemente, na opinião dele a obra melhora com a supressão. Stravinski indigna-se, não autoriza o mais mínimo corte e escreve ao amigo: "Aqui, você não está na sua casa”. É o fim de uma antiga amizade.

Kundera coloca o exemplo da relação entre compositor e intérprete para ilustrar todo tipo de relações na arte, entre elas a que aqui interessa: a tradução. De fato, não é infrequente comparar a interpretação - a atualização de uma peça musical, uma peça de teatro, um roteiro cinematográfico, etc. - com a tradução. Como também é habitual encarar a tradução como uma atividade hermenêutica, interpretativa. A própria etimologia de intérprete (intermediário) se ajusta bastante bem ao ato de traduzir, como também se ajusta ao ato de representar ou de tocar composições ideadas por outros. Deste ponto de vista, a tradução seria uma intermediação necessária para pôr em contato um texto e um leitor, como a interpretação o é para pôr em contato uma partitura e um ouvinte.

Mas prossigamos com a história de Ansermet e Stravinski. Comento a página de Kundera com um amigo músico e acha estranho. Lembra que, nalguma ocasião, Stravinski dissera que Ansermet conhecia melhor sua música que ele próprio. Por que de repente já "não está na sua casa"? Falamos do rol do autor, de seus direitos, e o amigo músico conta que Stravinski publicara as partituras de suas primeiras obras na Rússia. Depois da Revolução de 1917, viu-se privado de seus direitos de autor: qualquer pessoa podia tocar sua música em qualquer local e ele não recebia um só centavo. Para evitá-lo, ele reescreve parte dessas partituras, introduz pequenas 
mudanças, retoca as obras e as publica de novo como definitivas, canônicas, as únicas que podem ser consideradas autenticamente originais. Mas, desta vez, sujeitas a uma legislação que lhe permite receber dinheiro toda vez que uma formação musical quer interpretá-las.

No suposto de que as coisas fossem assim, podemos pensar que o fato de alterar uma obra de arte por razões fundamentalmente econômicas tira legitimidade ao compositor para condenar as alterações por razões estéticas de um diretor de orquestra? É o caráter das alterações o que as torna legítimas ou ilegítimas? A finalidade que procuram - estética, econômica, política, etc. - justifica sua oportunidade? Para Kundera, a coisa é clara. Não se trata nem de motivação nem de finalidade, mas de agente. Não se trata de ver por que é que se corta, se altera ou se modifica uma obra de arte, mas quem é que o faz, quem corta, altera ou modifica. Em arte, ninguém mais do que o autor está na própria casa.

Se uma obra de arte é a emanação de um indivíduo e de sua unicidade, é lógico que este ser único, o autor, possua todos os direitos sobre aquilo que é a emanação exclusiva dele próprio. (Kundera, 1993: 249)

O resto de agentes que intervém no processo tem, portanto, que obedecer aos desígnios do único proprietário, o indivíduo-autor. Estão em casa de outro e só podem fazer o papel de convidados. Quanto à obra, também não parece ter nenhum tipo de autonomia, nenhum papel além do de "emanação". De aí que:

Sem dúvida, seria possível escrever melhor uma ou outra frase de Em Busca do Tempo Perdido. Mas onde encontrar o louco que iria querer ler um Proust melhorado! (Kundera, 1993: 227) 
É verdade que os convidados - intérpretes, reescritores, leitores... - são autorizados a fazer alguma sugestão, comentar a decoração, apreciar a arquitetura. É, porém, o autor quem tem a última palavra, a definitiva. Um autor, aliás, abatido pela inevitável traição de que será objeto quando abandone este mundo e sua autoridade definhe. Esse momento em que os convidados, como herdeiros ingratos, distribuirão entre si os despojos dele e esquecerão as últimas vontades.

Meu amigo músico ainda conta mais coisas de Stravinski. Conta, por exemplo, que a certa altura o compositor operou uma espécie de reescrita de grandes músicos como Pergolesi ou Chaikovski. O que me lembra que, no ano 1981, Kundera escreve uma peça de teatro, Jacques e Seu Amo: Homenagem a Denis Diderot, que é uma variação do romance Jacques le Fataliste. Uma variação, não uma adaptação, apressa-se a afirmar Kundera no prefácio. As adaptações, as reescritas, são práticas de Reader's Digest, enquanto as variações são explorações das possibilidades de um assunto, apropriações das que o "autor soberano" é o adaptador (Kundera, 1990: 20). É claro que muitas grandes obras são mais ou menos variações de outras obras, mas enquanto se lhes puder atribuir o estatuto de variação - e não o de simples adaptação - podemos considerá-las produto de um autor soberano. Stravinski ou Kundera (ou Shakespeare ou Diderot) aproveitam temas de outros, tomam emprestados motivos e personagens, abordagens e técnicas, mas declaram-se sem restrições autores soberanos.

Variações e não adaptações. Onde reside a fronteira? E, nessa categoria, onde entram a tradução e a interpretação? Stravinski reescreve um tema de Pergolesi, mas não tolera que Ansermet ponha as mãos na sua obra. Kundera reescreve as aventuras de Jacques e de seu amo, mas exaspera-se quando a encenação dessa mesma peça foge de suas indicações explícitas, ao ponto de acabar por decidir só permitir que a encenem companhias de amadores ou com recursos escassos, porque "na arte, com efeito, nada há mais desastroso do que o dinheiro em abundância nas mãos de um imbecil sofisticado" (Kundera, 1990: 138). 
O próprio Kundera é, porém, consciente da sutileza dos limites do conceito de variação (um conceito musical adaptado à literatura): "Os diretores teatrais que tenham inclinações grafômanas [...] dirão a si próprios: se Kundera permitiu-se fazer uma variação sobre o romance de Diderot, por que não fazer, também, uma variação livre de sua variação livre?". É, por que não? Parece uma pergunta razoável. Mas Kundera responde: "não, porque é o método mais certo de armar um galimatias". Kundera parece querer fechar a porta atrás de si.

No entanto, para Kundera, as variações de Stravinski são perfeitamente lícitas. Porque:

Ele amou seu velho mestre como eu amei o meu. Ao acrescentar às melodias do século XVIII as dissonâncias do século $\mathrm{xx}$, talvez imaginava que poderia interessar seu mestre no outro mundo, que lhe mostraria alguma coisa importante sobre nossa época, que até poderia diverti-lo. Tinha necessidade de dirigir-se a ele, de falar com ele. A transcrição lúdica de uma obra antiga era para ele uma maneira de estabelecer uma comunicação entre os séculos. (Kundera, 1993: 72)

No entanto, os cortes de Ansermet na interpretação de Stravinski, ou as modificações feitas por um diretor belga na encenação de Jacques, são pastiches, abusos de alguém que, convidado de uma casa, quer impor nela seu próprio gosto, independentemente do gosto do proprietário. E são pastiches não porque Ansermet ou o encenador belga não sejam capazes de melhorar algum aspeto concreto dessas obras, mas por princípio. Lembremos: que doido quereria ler um Proust melhorado? Portanto, a obra é propriedade exclusiva do autor e de mais ninguém, e as reescritas são uma espécie de mal necessário, intermediários indesejáveis embora por vezes imprescindíveis.

Deste ponto de vista, não é nenhuma surpresa que Kundera tenha sido com frequência muito crítico com as traduções. É um 
desses autores que gostam de controlar as traduções de seus livros, tanto quanto gosta de controlar a encenação do seu teatro. De fato, um dos capítulos de A Arte do Romance é um dicionário de palavras-chave que, entre outras coisas, pretende evitar incompreensões das pessoas que o traduzam (Kundera, 1987). De esse modo, um romancista extraordinário e, simultaneamente, um excelente crítico literário é também, quase por princípio, um zeloso defensor da preeminência da autoria por cima da tradução, ou pelo menos é o que se deduz das ideias expostas até aqui, ou de outras especificamente referidas a problemas de tradução como a seguinte:

Minha velha experiência com os tradutores: se eles deformam você, nunca é nos detalhes insignificantes mas sempre no essencial. O que não é sem lógica: é na novidade (nova forma, novo estilo, nova maneira de ver as coisas) que se encontra o essencial de uma obra de arte, e é certamente o novo que, de um modo inteiramente natural e inocente, se choca com a incompreensão. (Kundera, 1993: 226)

Ou esta:

Vamos admitir, sem nenhuma ironia: a situação do tradutor é extremamente delicada: ele deve ser fiel ao autor e, ao mesmo tempo, permanecer ele mesmo; como fazer? Ele quer (consciente ou inconscientemente) investir o texto de sua própria criatividade; como para tomar coragem, escolhe uma palavra que aparentemente não trai o autor mas depende de sua própria iniciativa. É o que constato neste momento em que revejo a tradução de um pequeno texto meu: escrevo "autor" e o tradutor traduz "escritor"; escrevo "escritor", ele traduz "romancista"; escrevo "romancista", ele traduz "autor"; quando digo "versos", ele traduz "poesia"; quando digo "poesia", ele traduz "poemas". Kafka diz "ir", os tradutores "andar". Kafka diz "qualquer elemento", os tradutores "nada dos elementos", "nada em comum", "nem 
um único elemento". Kafka diz ter "a sensação de se extraviar", dois tradutores dizem "ter a impressão...", enquanto o terceiro (Lortholany) traduz (com razão) ao pé da letra e prova desta forma que a substituição de "sensação" por "impressão" não é de modo algum necessária. Essa prática sinonimizadora tem ar inocente, mas seu caráter sistemático embota inevitavelmente o pensamento original. E depois, por que, diabos? Por que não dizer "ir" se o autor disse "gehen"? Ah, senhores tradutores, não nos sinonimizem! (Kundera, 1993: 97-98)

Ou ainda, para finalizar:

A autoridade suprema para um tradutor deveria ser o estilo pessoal do autor. Mas a maior parte dos tradutores obedece a uma outra autoridade: àquela do estilo comum do "bom francês" (do bom alemão, do bom inglês, etc.), a saber do francês (do alemão etc.) que se aprende no colégio. (Kundera, 1993: 99)

Incompreensão, egocentrismo, academicismo... Ou a tradução pensa demais em si mesma (e quem traduz quer deixar nela um cunho pessoal) ou pensa demais no leitor (na fisionomia da língua de chegada, no "grande estilo"), mas nunca pensa o suficiente no autor. Tradutoras, tradutores, vocês não estão na vossa casa! Não podem mudar a cor das paredes ou a orientação da luz, embora, talvez nesse ponto, a vossa língua não use a mesma cor, ou o sol seja menos forte. Se o que pretendem é mudar tudo, construam a vossa própria casa!

Mas afinal, o que é que significa construir uma casa própria, isto é, virar autor? Significa ter que inventar personagens e histórias? Não necessariamente: reparemos nos personagens de Jacques e Seu Amo, de Kundera. Reparemos nas situações, nas histórias, no enquadramento, etc. Tudo é igual a Diderot. Reparemos na língua, 
na mentalidade da peça: não são de Diderot, mas de Kundera. Mas não são precisamente essas as acusações que ele próprio fazia aos tradutores?: não respeitar o estilo pessoal, apropriar-se do tom, aproximá-lo do leitor, interpretar seu sentido. É verdade, Kundera não está fazendo uma tradução, mas uma variação. Mas: onde reside exatamente a fronteira? Não poderia residir simplesmente no estatuto do agente? Entre a tradução, a adaptação e a variação existe um contínuo. Entre o tradutor e o autor não. São entidades discretas, pelo menos em relação a uma obra concreta. São as credenciais de autor as que outorgam autoridade. Uma tradução é aquilo que fazem tradutoras e tradutores. É a atribuição do papel ao agente o que separa nitidamente uma coisa da outra, especialmente quando o resultado, a obra, se situa num espaço indefinido, quando a pertença a uma série, a uma tradição - quando a dívida para com outra obra - é particularmente evidente, como acontece com o Jacques e Seu Amo de Kundera, herdeiro de Jacques le Fataliste de Diderot, herdeiro ele também do Tristram Shandy de Sterne. ${ }^{2}$

\section{Autoria e tradução, distinta condição?}

A perspectiva de Kundera sobre a autoria e a autoridade é essencialista, no sentido que dá a esse termo, por exemplo, a estudiosa da tradução Rosemary Arrojo:

O fundamento de toda perspectiva essencialista se encontra na crença de que o significado de algum modo está presente no texto. Se isto é assim, portanto, deve haver um modo certo de extrair esse significado da linguagem que supostamente o protege. [...] Nessas condições ideais, deveríamos ser capazes de achar a forma adequada de ler ou de traduzir, que, aliás, seria de aplicação universal e suporia a eliminação de qualquer vislumbre de subjetividade ou rastro ideológico. (Arrojo 2002: 28) 
A crise da autoria, a morte do autor, é um assunto muito apreciado pela corrente que Arrojo chama de antiessencialista, uma corrente que a autora identifica mais ou menos com o pós-estruturalismo. Não há texto que trate da morte do autor que não cite o famoso artigo de Barthes (1968) que justamente leva esse título, "A morte do autor". Barthes denuncia nele a falsidade da origem: não é possível estabelecer a origem de um texto em um autor, uma vez que este "deveria saber que a "coisa" interior que tem intenção de "traduzir" não é em si mesma nada mais do que um dicionário já composto, no qual as palavras não se podem explicar senão a través de outras palavras, e assim indefinidamente" (Barthes, 1968: 69). Desta perspectiva, não é possível dizer nada verdadeiramente novo que seja inteligível, pois todo texto faz parte de uma série, diluise em um mar de sentidos impossível de fixar, de deter. Barthes (1971) distingue a obra do texto precisamente em função do "mito da filiação". A obra tem um pai proprietário, o autor, enquanto o texto se lê "sem a inscrição do pai". Procurar as fontes ou as influências de uma obra é satisfazer o mito da filiação. A intertextualidade, portanto, não deve confundir-se com a procura da origem, porque em um texto não há origem, não há linearidade nem fonte: seu sentido prolifera em todas as direções, e não apenas desde a fonte, a origem, até a consecução, ao produto obra. Como dizia Diderot, afinal o plagiário vai ser o meu antecessor.

Mas proclamar a morte do autor significa negar a existência de um agente? É claro que não. Matar o autor é privá-lo da propriedade do texto, é tirar-lhe a chave que fecha esse texto (ou que volta a abri-lo para retocá-lo), que o fixa e lhe dá uma essência. O papel da autoria não interessa como mão que materializa o texto. Não menos iniludível que o artigo de Barthes - nem menos citado - é o de Michel Foucault (1969) "O que é um autor?". Para Foucault, a autoria é fundamentalmente um determinado papel relativamente ao discurso: "garante uma função classificatória; um determinado nome permite reagrupar certo número de textos, delimitá-los, excluir alguns, opô-los a outros. Além disso, estabelece uma relação 
dos textos entre si". Daí que "se se demonstrara que Shakespeare escreveu o Organon de Bacon simplesmente porque é o mesmo autor quem escreveu as obras de Bacon e as de Shakespeare, estaríamos frente a um [...] tipo de mudança que modifica completamente o funcionamento do nome do autor" (Foucault, 1969: 337). A autoria, na função social que lhe atribuímos, dá um determinado sentido a um discurso. Inclusive um sentido histórico que a modernidade considera essencial, também para sua avaliação estética:

- Estranha coisa - digo. - Se O Bosque Harmonioso datar do século XVI, consideramo-lo uma obra-prima. Escrito posteriormente, não. Que mistério este que faz com que a mesma obra possa ser ou não ser! Se se descobrisse que o Partenon, aquele mesmo Partenon, fora construído ontem, deixaria de ser o que é, deixaria de nos emocionar como nos emociona quando o sabemos construído no tempo de Fídias? (Abelaira, 1982: 138)

Sabemos bem, portanto, que a autoria - com sua contextualização histórica - representa um papel importante na avaliação da obra de arte. Importa quem fala? Importa sim, apesar de tudo. Como da morte de Deus, da morte do autor apenas souberam, de fato, umas poucas pessoas. E da mesma forma que, ao longo da história, algumas de essas pessoas que pensaram ter visto a morte de Deus decidiram silenciá-la (para conservar os privilégios, como Voltaire, ou para não tirar um consolo aos que não têm mais nada, como Unamuno), também a maior parte da crítica artística se recusou a enterrar a autoria. Porque se o autor morreu, como é possível que seja um cadáver tão sadio? Será que todos esses augúrios estão errados e não existe tal cadáver? Por que razão o pós-estruturalismo anuncia a morte da autoria? Pela mesma razão que Nietzsche anunciou a morte de Deus: não se trata de dizer uma verdade, mas de dizer um projeto. Deus ou a autoridade apenas podem morrer - ou serem mortos, ou ressuscitar - de uma forma: enunciando. Pelo 
menos, de uma perspectiva que tem como critério não a realidade, nem a verdade, mas a vontade. A morte do autor - como qualquer enunciado herdeiro de Nietzsche - não é uma constatação, é um desejo. Daí que o que, agora e sempre, interessa às pessoas que traduzimos não é se a autoria é verdadeiramente um doente imaginário ou se a coisa é séria, porque isso também depende de nós. O que nos interessa, afinal, é esclarecer se para nós, tradutores, é conveniente que o autor se evapore.

\section{Não se pode saber o que nos espera no passado}

Muito antes do pós-estruturalismo, a reflexão sobre a origem dos textos, a autoria e todas essas questões já tinha dado frutos bem gostosos. De fato, muitas das contribuições posteriores reconhecem ser devedoras de um personagem fundamental nesse sentido, Jorge Luis Borges. É em Borges onde, da perspectiva da tradução, acho que podemos encontrar uma ótima inspiração para responder à pergunta de se é ou não conveniente para nós assassinar a autoria.

Durante séculos, a tradutodologia andou às voltas com o problema da natureza da relação entre dois textos aos que chamamos original e tradução. Ninguém, porém, contestou a posição precedente de um em relação ao outro: parece evidente que o original precede a tradução, lhe é anterior. De uma perspectiva linear como a nossa, precedência significa preeminência, por mais que, por vezes, protestemos contra este axioma quando nos prejudica. Pois bem, Borges decide prescindir desse aspeto. Borges atua como se a precedência não significasse nada, de fato, como se não existisse.

Jorge Luis Borges dedicou à tradução alguns textos e um punhado de comentários. Embora tudo isso se apresente um pouco disperso e bastante conciso, conseguiu um impacto muito considerável no pensamento tradutológico posterior, e provavelmente ainda teria conseguido mais se, com frequência não nos deixássemos influenciar pelos preconceitos de gênero que fecham um texto na 
gaveta do conto ou do poema e não o deixam sair quando se trata de reflexionar ou de pesquisar. Um estudioso da tradução tão sólido e citado como é Georges Steiner chegou a afirmar que o conto "Pierre Menard, autor do Quixote", de 1939, "é provavelmente o mais agudo e denso comentário que se tenha dedicado ao tema da tradução" (Steiner, 1975: 90). E para Dominique Louisor, "a tradução é uma pedra de toque da obra de Borges" (Louisor, 1995: 209). Em minha opinião, a contribuição fundamental da aproximação de Borges à tradução é a mudança de ponto de vista. O que, durante séculos, foi - para muitas pessoas ainda é - o núcleo das preocupações da tradutodologia, isto é, a relação entre original e tradução (e toda a série de conceitos associados a essa relação: fidelidade, equivalência, literalidade, etc.) não tem importância para o nosso autor:

A conceição borgiana da tradução se constroi sobre a recusa do que tradicionalmente houve no centro da reflexão sobre essa atividade. Não é a relação entre o texto original e a sua tradução o que estuda, mas as relações que mantêm várias traduções entre si. (Louis, 1996: 291)

Esse ponto de vista está perfeitamente expresso numa brincadeira famosa de Borges: a propósito do romance Vathek, conta que William Beckford escreveu a história em francês, e Hentley a traduziu para o inglês. Pois bem, "o original é infiel à tradução" (Borges, 1952: 207). Ou em outra brincadeira no mesmo sentido: no conto sobre Pierre Menard, diz-se que entre as obras dele poderia haver uma "versão literal da versão literal que Quevedo fez da Introduction à la vie devote de são Francisco de Sales" (Borges, 1944: 50, nota 1). Quer dizer, uma tradução para o francês da tradução espanhola do texto francês de são Francisco. Tudo literal, é claro. Borges, portanto, usa a ironia e a brincadeira sutil para atacar dois dos grandes mitos da tradução: a fidelidade e a literalidade, e para nos situar fora das clássicas dicotomias da tradução 
literal e tradução livre, ou da tradução fiel, mas insulsa, e a tradução brilhante, mas traidora.

As brincadeiras de Borges emaranham esse tipo de relações, invertem seus termos ou as levam até as últimas consequências com a finalidade de nos mostrar até que ponto podem ser absurdas. Não com o objetivo de mostrar como é capaz de construir paradoxos e contar piadas, mas para nos ajudar a pensar fora desses dilemas. Outro exemplo: o caso de Fitzgerald e a tradução do persa para o inglês das Rubayat de Omar Khayam (Borges, 1952: 118 e s.). Fitzgerald é um poeta inglês "medíocre" (segundo Borges) da metade do século XIX; Omar Khayam é um estudioso persa do século XI que escreve poemas breves como distração da Astronomia e da Filosofia, suas atividades sérias. No entanto, a versão inglesa das Rubayat é extraordinária (sempre segundo Borges). A tradução conseguiu um milagre, Fitzgerald "deu a Omar Khayam um lugar perpétuo entre os maiores poetas da Inglaterra":

Acontece um milagre: da fortuita conjunção de um astrônomo persa que condescendeu à poesia e de um inglês excêntrico que percorre, talvez sem entendê-los por completo, livros orientais e hispânicos, surge um extraordinário poeta, que não se parece a nenhum dos dois. (Borges, 1952: 73)

Que importa se Fitzgerald é um colonialista que reescreve os poetas persas com um espírito desrespeitador que nunca teria coragem de se permitir com uma literatura europeia? O importante é o valor literário das Rubayat em inglês. Borges sim quer ler um Proust melhorado, sempre que se trate, com efeito, de melhorar do ponto de vista estético (não de cortar para poupar páginas, por exemplo). A tradução é um gênero literário mais. Para Borges, não há fronteiras entre original e tradução: tudo são reescritas. Entre uma variação na linha do Jacques de Kundera e uma tradução não há diferenças essenciais; no máximo haverá diferenças de grau: tudo são elementos de uma série, plágios de plágios, paráfrases. 
E não necessariamente arrumados em uma linha temporal. Já dissemos que a preeminência não faz sentido aqui. O passado não é menos incerto nem menos constantemente construído e reconstruído do que o futuro:

Se não me engano, os heterogêneos textos que enumerei parecem-se com Kafka; se não me engano, nem todos se parecem entre si. Este último fato é o mais significativo. Em cada um desses textos, em maior ou menor grau, encontra-se a idiossincrasia de Kafka, mas, se ele não tivesse escrito, não a perceberíamos, vale dizer, não existiria. [...] O fato é que cada escritor cria seus precursores. Seu trabalho modifica nossa concepção do passado, como há de modificar o futuro. (Borges, 1952: 98)

\section{A religião ou o cansaço}

$\mathrm{O}$ assalto à preeminência da precedência é um rasgo essencial na morte do original. A legitimidade não é para aqueles que chegarem primeiro, mas para aqueles que trabalharem melhor, para aqueles que forem capazes de combinar os elementos de uma forma mais bela. Já não há nenhuma competição, e por isso não é preciso preocupar-se com ocupar o lugar do primeiro: todos estão convidados a criar e a recriar. De fato, toda a gente faz isso com os mesmos elementos, ensaiando novas combinações, refazendo sem fim. Tudo faz parte de uma série - talvez infinita, com certeza indefinida, como a Biblioteca de Babel — de reescritas, um grande armazém de rascunhos. 
Pressupor que toda recombinação de elementos é obrigatoriamente inferior a seu original, é pressupor que o rascunho 9 é obrigatoriamente inferior ao rascunho $\mathrm{H}-$ já que não pode haver senão rascunhos. $O$ conceito de texto definitivo não corresponde senão à religião ou ao cansaço. (Borges, 1932: 255)

Como bem salienta Louis (1996: 292), Borges evita comparar o rascunho 9 com o 8: a linearidade do nosso senso comum faria com que caíssemos na tentação da precedência. Que importância pode ter que o rascunho $\mathrm{H}$ seja datado antes ou depois do que o rascunho 9? Suponhamos que o leitor X lê primeiro o $\mathrm{H}$ e depois o 9. Quem sabe de que forma a compreensão e o prazer da primeira leitura vão ser modificados pela segunda? Quem sabe se precisará ler o rascunho beta para compreender a secreta afinidade entre o 9 e o H? Que vai acontecer se o acaso levar a leitora Y a percorrê-los noutra ordem?

Desta perspectiva, que sentido pode ter que uma tradução tenha como fim principal a fidelidade? O que conta realmente é atingir objetivos estéticos. A fidelidade é um objetivo duplamente triste, porque é inútil e sobretudo é impossível. Daí que Borges a ridicularize sutil, mas radicalmente, no conto "Pierre Menard, autor do Quixote". Como toda a gente sabe, Pierre Menard é um autor simbolista francês que se propõe a estranha tarefa de escrever o Quixote; não de copiá-lo nem de recriá-lo, mas de escrevê-lo, palavra por palavra. Consegue fazê-lo parcialmente: na hora da morte deixa os capítulos nono e trigésimo oitavo, e um fragmento do capítulo vigésimo segundo. Aparentemente o resultado é idêntico letra por letra ao de Cervantes. Mas Borges mostra como a leitura de um Quixote do século XVII difere completamente da de um Quixote escrito a inícios do XX. Supondo que um empreendimento tão absurdo como o que Menard se propõe possa atingir-se, no fundo é completamente impossível: o mesmo livro é outro livro. ${ }^{3}$ Steiner (1975:90-93) interpreta o 
conto de Borges como uma amostra da nostalgia que provoca a impossibilidade da tradução. Arrojo (2002), no entanto, acha que se trata de uma sátira da absurda pretensão de traduzir literalmente (o limite ideal de uma tradução literal, logicamente, é a criação de um texto idêntico):

Como todo tradutor que acredita na estabilidade $a b-$ soluta e "sagrada" do original, Menard simplesmente tenta guardar a máxima fidelidade ao texto de Cervantes. Mas o que o próprio senso comum e a maioria dos especialistas aceitam como a função mais sisuda de todo tradutor que se orgulhe de sê-lo revela-se de forma brilhante na história de Borges como uma empresa fantasiosa e absurda. (Arrojo, 2002: 37)

No que a autoria diz respeito, a conclusão do ponto de vista de Borges parece clara: uma vez apagados os limites entre tradução e original, uma vez ridicularizada a pretensão submissa de fidelidade de uma para com a outra, não há razão para definir dois papeis para uma mesma agência: a criação de rascunhos. E ambas as etiquetas se referem a alguma coisa que não faz sentido caracterizar como uma espécie de demiurgo gerador de originais absolutos e intocáveis, mas como um elo, um nó numa enorme rede que constitui o edifício da literatura humana.

\section{As guerras de autoria e tradução}

Mas sejamos práticos: tudo isto, onde nos leva? Ao longo da história, as pessoas que se dedicaram à profissão de traduzir aceitaram com frequência um papel de subordinação com respeito ao original. De fato, durante muitos anos, foram editadas inúmeras traduções literárias nas que nem sequer constava que o fossem, e 
menos ainda o nome da pessoa que as fizera. Ainda hoje as traduções são pagas por palavras ou por caracteres: não é normal um autor literário receber da editora em função da extensão do seu livro. As ideias de Borges - e de toda uma série de contribuições na mesma linha, das que já vimos algum nome - permitem rever em profundidade a questão. Estudos sobre a tradução como os de Barthes, Derrida ou Arrojo parecem questionar definitivamente a figura do autor, parecem tentar dissolvê-la. Kundera revela-se contra essa dissolução, interpreta-a como um sintoma do fim do indivíduo:

Os Tempos Modernos fizeram da pessoa, do indivíduo, de um ego pensante, o fundamento de tudo. De esta concepção do mundo resulta também a nova concepção da obra de arte, que se torna a expressão original de um indivíduo único. (Kundera, 1993: 321)

O fim do indivíduo - que seria um indício fundamental do fim do autor - suporia a consecução do sonho totalitário de apagar a fronteira entre o privado e o público, o coletivo. O respeito pelos direitos autorais nasce com a mentalidade individualista que consagra a existência da privacidade e o direito de cada pessoa a desfrutar dela. Se o que faz um indivíduo - a obra dele - passa automaticamente a ser de domínio público, se não pode controlar que seja manipulada nem preservar sua integridade exatamente na forma como foi concebida por alguém que se considera uma individualidade radical, então é que o indivíduo está a recuar. E, segundo o autor checo, atualmente é o que está acontecendo. A época do indivíduo autor foi como um relâmpago na história, e o fulgor desse relâmpago já começou a desvanecer-se. Como pode alguém - um roteirista, por exemplo - reclamar direitos morais artísticos sobre um filme que custa milhões de reais e no qual intervêm centenas de pessoas? A vontade criadora do indivíduo se dissolve no magma coletivo e a obra vira anônima. Afinal, é ao 
público, ao mercado, às tendências, à estatística a quem se dá a responsabilidade do resultado artístico.

O que da perspectiva da tradução aconteceu nas últimas décadas não tem, no entanto, esse caráter. Não há nenhuma ameaça de tradutoras e tradutores contra a figura do autor indivíduo, contra a individualidade que implica uma autoria reconhecida. Bem ao contrário: o que pretendem as pessoas que traduzem literatura é um lugar ao sol, um espaço no pedestal da individualidade. E o que por vezes reclama o coletivo dos indivíduos autores é contra essa intrusão nos limbos artísticos. "O que é que pensam esses escrivões, esses artesões?", parecem dizer. "Querem compararse conosco, com os habitantes do Parnaso". Essa é, afinal, a questão. O que Borges nos ensinou já há muitos anos é que somos tão indivíduos quando os indivíduos autores, ou então que eles são iguais a nós. Não deve haver subordinação simbólica entre as diferentes reescritas, porque não a há estética. Cada rascunho é um fractal, um compêndio de toda a literatura. Mas ao mesmo tempo é uma peça única, uma combinação excepcional e necessariamente irrepetível (nem o próprio Pierre Menard conseguiu repetir o Quixote, apesar de escrevê-lo novamente palavra por palavra, aparentemente idêntico).

Exigir fidelidade a uma tradução literária não faz parte do espírito que é o fundamento do indivíduo, e sim do espírito que é o fundamento do feudalismo e do patriarcado. Em troca, aceitar que a própria obra, sem deixar de ser o produto de uma conjunção única, é uma reescrita e pode e deve ser reescrita por outra individualidade que ao fazê-lo vai renová-la, vai iluminá-la de outro ângulo ou vai situá-la noutro nó da rede, é fazer possível a continuidade da ideia de indivíduo numa comunidade de pessoas livres, talvez com divisão do trabalho, mas sem hierarquias. A literatura não é um filme de milhões de reais, com uns produtores que provavelmente não sejam senão uma entidade financeira sem rosto - com rostos intercambiáveis, sem indivíduos. Atendendo a que, na literatura, ninguém é dono de nada mais além da caneta ou do computador, 
e toda a gente usa os mesmos materiais - a tradição, a língua - , ainda há aqui espaço para a individualidade: cada contribuição individual redesenha de certo modo o conjunto.

Também Kundera acha preocupante que a propriedade intelectual seja cada vez mais uma questão de corporações, de sociedades anônimas e de escritórios com titulares clonados. Autoria e tradução - e todas as formas de rescrita - não deveriam brigar pelo direito a criar obras de arte. A sobrevivência do gosto individual frente à ditadura da audiência passa pelo reconhecimento de todas as agências que intervêm na criação, pelo fim da hierarquia que submete umas (traduções, revisões, leituras, etc.) às outras (autoria, edição, crítica autorizada, etc.). Que cada um assuma e assine sua responsabilidade individual na criação: esse é o objetivo. Quando a autoria oculta todas as outras mãos que intervieram no processo de criação é quando realmente o leitor é enganado. $\mathrm{O}$ que leio quando leio uma tradução de Kundera para catalão não são as palavras de Kundera. Essas palavras, literalmente, são de Gustova, sua tradutora. É preciso que Gustova assuma a responsabilidade delas, e que eu como leitor possa atribuir na justa medida o mérito ou o demérito que considere conveniente. É preciso que saiba quando leio se quem tenho na frente é Cervantes ou é Pierre Menard, ou os dois em simultâneo.

\section{Conclusão}

Concluindo, acho que Borges não nos propõe matar o autor para contribuir para o fim do indivíduo, e sim para o fim do feudalismo literário, a queda da monarquia absoluta da autoria. Não é que não se possa corrigir, alterar, traduzir, reler, reescrever... É que isso é tudo o que se faz: cada novo texto recoloca a totalidade dos textos anteriores, corrige-os, altera-os. Junta textos que nunca teriam conhecido vizinhança nenhuma e chama-os de precursores; provoca impressões que nunca teria suspeitado, porque é lido noutro mundo 
linguístico e cultural, de outra posição textual. O que não se pode parar é justamente isso, a reescrita constante de qualquer texto, inclusive - apesar da brincadeira de Borges - dos religiosos. Menard, coitado, faz uma tentativa, e só consegue um pastiche com lampejos simbolistas. O que Borges propõe é precisamente a essência do individualismo: a igualdade essencial que impede medir com a mesma vara, quer dizer, a igualdade na diferença. $\mathrm{O}$ fim da condição de súbditos, a instauração da democracia criativa em que todos são responsáveis de seus atos e ninguém usurpa nem permite que usurpem seu lugar. A autoria, portanto, é nossa. Mas não de todas as pessoas, senão de cada uma delas.

\section{Notas}

1. Uma versão catalã deste artigo foi publicada na revista Quaderns: Revista de Traducció, no 16 (2009), da Faculdade de Tradução e Interpretação da Universidade Autônoma de Barcelona.

2. Consciente de até que ponto determinadas partes de seu romance estão próximas da tradução e do plágio, o próprio Diderot, quase no final da obra, salvaguarda: "Voici le second paragraphe, copié de la vie de Tristram Shandy, à moins que l'entretien de Jacques le Fataliste et de son maître ne soit antérieur à cet ouvrage, et que le ministre Sterne ne soit le plagiaire, ce que je ne crois pas, mais par une estime toute particulière de $\mathrm{M}$. Sterne, que je distingue de la plupart des littérateurs de sa nation, dont 1'usage assez fréquent est de nous voler et de nous dire des injures" (Diderot, 1796: 301).

3. Borges leva o jogo até o extremo e chega a dizer que por vezes imagina que Menard conseguiu seu objetivo de escrever todo o Quixote, e que quando folheia um exemplar chega a reconhecer aqui e ali o estilo de seu amigo francês. Se todo autor cria seus predecessores, por que não pode influenciar o estilo deles? 


\section{Bibliografia}

ABELAIRA, Augusto (1982). O Bosque Harmonioso. Lisboa: O Jornal.

ARROJO, Rosemary (2002). "La reevaluación del papel del traductor en el postestructuralismo: Nietzsche, Borges y la compleja relación entre Origen y Reproducción”. Em: Álvarez, Román (ed.). Cartografías de la traducción: del postestructuralismo al multiculturalismo. Salamanca: Almar, p. 27-41.

BARTHES, Roland (1968). "La muerte del autor”. A: El susurro del lenguaje: más allá de la palabra y de la escritura. Trad. de C. Fernández Medrano. Barcelona: Paidós, 2002, p. 65-71.

BARTHES, Roland (1971). "De la obra al texto". Em: El susurro del lenguaje: más allá de la palabra y de la escritura. Trad. de C. Fernández Medrano. Barcelona: Paidós, 2002, p. 73-82.

BORGES, Jorge Luis (1932). Discusión. Madrid: Alianza, 2003 (El Libro de Bolsillo. Biblioteca Borges; 11).

BORGES, Jorge Luis (1952). Otras inquisiciones. Madrid: Alianza, 2000 (El Libro de Bolsillo. Biblioteca Borges; 6).

BORGES, Jorge Luis (1944). Ficciones. Madrid: Alianza, 1989 (El Libro de Bolsillo; 320).

DIDEROT, Denis (1796). Jacques le Fataliste et son maîtres. Paris: Flammarion, 1997.

FOUCAULT, Michel (1969). “¿Qué es un autor?”. Em: Entre filosofía y literatura: obras esenciales, volumen I. Traducció de Miguel Morey. Barcelona: Paidós, 1999, p. 329-360.

GARGATAGLI, Ana; López Guix, Juan Gabriel (1992). "Ficciones y teorías en la traducción: Jorge Luis Borges”. Livius: Revista de Estudios de Traducción, núm. 1, p. 57-67. 
KUNDERA, Milan (1990). Jacques et son maître: hommage à Denis Diderot en trois actes. París: Gallimard, 2003 [Edició catalana: Jacques i el seu amo: homenatge a Denis Diderot. Barcelona: Edicions del Mall, 1987. Trad. de Joan Tarrida].

KUNDERA, Milan (1993). Les testaments trahis. París: Gallimard, 2005 (Folio; 2703) [Edició catalana: Els testaments traïts. Barcelona: Destino, 1994. Trad. de Carme Geronès i Carles Urritz. Edició castellana: Los testamentos traicionados. Barcelona: Tusquets, 1994. Trad. de Beatriz de Moura].

KUNDERA, Milan (1987). L'art de la novel-la. Barcelona: Destino. Trad. de Joan Tarrida.

LOUIS, Anne Marie (1996). "La traduction selon Jorge Luis Borges". Poétique: Revue de Théorie et d'Analyse Littéraires, núm. 107 (Septembre), p. 289-300.

LOUISOR, Dominique M. (1995). "Jorge Luis Borges and Translation”. Babel, v. 41, núm. 4, p. 209-215.

PETRILLI, Susan (2003). “Translatin with Borges”. Em: Petrilli, Susan (ed.). Translation Translation. Amsterdam: Rodopi, p. 517-530.

RODRÍGUEZ, Luisa Fernanda (1992). "Jorge Luis Borges and the Debate of Translation”. Livius, núm. 2, p. 243-252.

STEINER, Georges (1975). Después de Babel: aspectos del lenguaje y la traducción. Madrid: Fondo de Cultura Económica, 2001. 